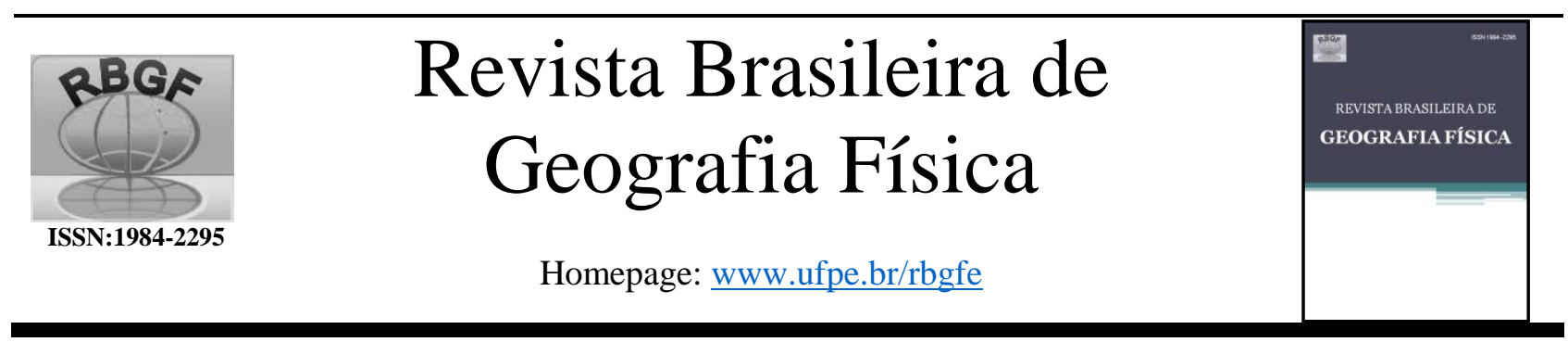

\title{
Caracterização Físico-Química, Química e Quimiométrica de Águas Subterrâneas dos Aquíferos Pirabas e Barreiras em Municípios do Estado do Pará
}

\author{
Emerson Renato Maciel da Silva ${ }^{1}$, Luiz Gonzaga Silva Costaㄹ, Antônio dos Santos Silva ${ }^{3}$, Ewerton Carvalho \\ de Souza ${ }^{4}$, Ivan Carlos da Costa Barbosa ${ }^{5}$
}

${ }^{1}$ Engenheiro Ambiental e de Energias Renováveis, Universidade Federal Rural da Amazônia, e-mail: emersonrvs255@gmail.com. ${ }^{2}$ Doutor em Ciências Agrarias, Universidade Federal Rural da Amazônia, e-mail: luizgonzagacosta53@gmail.com. ${ }^{3}$ Mestre em Química, Universidade Federal do Pará, e-mail: ansansil@ superig.com.br. ${ }^{4}$ Mestre em Química, Universidade Federal do Pará, e-mail: ewcarvalho@yahoo.com.br. ${ }^{5}$ Mestre em Química, Universidade Federal do Pará, e-mail: ivan.barbosa@ufra.edu.br.

Artigo recebido em 13/11/2017 e aceito em 30/05/2018

\begin{abstract}
R E S U M O
A extração de águas subterrâneas é vista como a principal fonte alternativa para suprir a escassez de água potável, levando a uma preocupação acentuada quanto a sua qualidade. Assim, o presente trabalho teve como objetivo caracterizar as águas subterrâneas dos aquíferos das formações Pirabas e Barreiras através de parâmetros físico-químicos e químicos de qualidade da água e aplicação de métodos estatísticos multivariados na avaliação dos resultados. A pesquisa foi desenvolvida nos municípios de Benevides, Barcarena, Abaetetuba e Capanema, no Estado do Pará. Foram determinados in situ o potencial hidrogeniônico ( $\mathrm{pH}$ ), turbidez (Turb), oxigênio dissolvido (OD), condutividade elétrica (CE), temperatura (Temp) e sólidos totais dissolvidos (STD). Em laboratório, foram determinadas as concentrações de acidez (ACD), alcalinidade (ALC), cloreto $\left(\mathrm{Cl}^{-}\right)$, dureza total (DT) e os teores de cálcio $\left(\mathrm{Ca}^{2+}\right)$ e magnésio $\left(\mathrm{Mg}^{2+}\right)$. Através da análise de componentes principais observou-se nitidamente a formação de dois grupos distintos formados pelas amostras de água provenientes das formações Pirabas e Barreiras. De acordo com os resultados obtidos por meio das análises físicoquímicas e químicas, assim como a aplicação da ANOVA, seguida do teste de Tukey, e da estatística multivariada, foi possível caracterizar as águas subterrâneas oriundas das formações Pirabas e Barreiras. A caracterização das águas subterrâneas pode ter sofrido influência das características geográficas de cada município e, as peculiaridades dos principais aquíferos. Quanto à qualidade das amostras de água subterrânea pode-se aferir que as águas consumidas pelos moradores necessitam de um tratamento prévio, quanto aos padrões de potabilidade recomendados pelas legislações vigentes.
\end{abstract}

Palavras-chave: aquífero; recurso hídrico; água subterrânea.

\section{Physical-Chemical, Chemistry and Chemometric Characterization of Underground Waters from Pirabas and Barreiras Aquifers in Municipalities of the State of Pará}

\begin{abstract}
A B S T R A C T
Groundwater extraction is seen as the main alternative source to supply the drinking water shortages, leading to a haigh concern about its quality. Thus, the present work aimed to characterize the groundwater of Pirabas and Barreira aquifers through physicochemical and chemical parameters of water quality and the application of multivariate statistical methods in the evaluation of the results. The research was developed in the municipalities of Benevides, Barcarena, Abaetetuba and Capanema in the State of Pará. In situ, the potential of hydrogen (pH), turbidity (Turb), dissolved oxygen (OD), electrical conductivity (EC), temperature (Temp) and total dissolved solids (STD) were determined. In the laboratory, the concentrations of acidity (ACD), alkalinity (ALC), chloride (Cl-), total hardness (DT) and calcium (Ca2 +) and magnesium $(\mathrm{Mg} 2+)$ concentrations were determined. Through the principal componentes analysis, the formation of two distinct groups by the water samples from the Pirabas and Barreiras aquifers was clearly observed. According to the results obtained through the physicochemical and chemical reviews, as well as the ANOVA application, followed by the Tukey test and the multivariate statistics, it was possible to characterize the groundwater from the Pirabas and Barreiras formations. The characterization of groundwater may have been influenced by the geographical characteristics of each municipality and the peculiarities of the main aquifers. Regarding the groundwater samples quality, the water consumed
\end{abstract}

Silva, E. R. M., Costa, L. G. S., Silva, A. S., Souza, E. C., Barbosa, I. C. C. 
by the residents requires a prior treatment, in terms of the standards of drinking water recommended by the current legislations.

Keywords: aquifer; water resource; groundwater.

\section{Introdução}

A água constitui-se como a fonte líquida mais abundante do planeta, exerce papel fundamental no que refere-se a existência da vida, sendo indispensável para o ser humano e os demais seres vivos, além de ser o suporte essencial aos ecossistemas. É utilizada para ingestão humana e para atividades socioeconômicas, sendo retirada de fontes como: rios, lagos, represas e aquíferos. É um elemento que exerce grande influência na saúde, na qualidade de vida e no desenvolvimento das populações (Scuracchio, 2010).

Segundo Silva e Araújo (2003), em meio às inúmeras fontes de captação da água, destinada ao consumo humano, uma delas é o manancial subterrâneo, onde a captação pode ser proveniente de um aquífero confinado ou artesiano, localizado entre duas camadas relativamente impermeáveis, ou também a partir de aquíferos livres próximos a superfície.

De acordo com Bastos (2013), verifica-se uma preocupação acentuada sobre a escassez de água destinada para consumo humano. Nesse contexto, evidencia-se uma utilização de soluções alternativas de abastecimento de água para potabilidade. Assim, Kemerich (2008) aborda que as comunidades voltaram-se para a extração de águas subterrâneas, o que está associado ao baixo custo de capitação e, ao fato de que, na maioria das vezes não se faz necessário o tratamento prévio da água, pois os processos de infiltração e depuração do subsolo promovem a purificação natural da água, tornando-a potável.

No Estado do Pará, apesar de apresentar uma densa rede de drenagem superficial, formada por muitos rios, cerca de $70 \%$ dos municípios paraenses utilizam como fonte de abastecimento as águas subterrâneas, devido ao baixo custo de produção (CPRM, 2013). Segundo Condurú (2012), a Companhia de Saneamento do Pará (COSANPA) atende apenas 59 municípios, correspondendo a aproximadamente $41 \%$ dos municípios paraenses, o que leva a uma maior exploração dos recursos subterrâneos disponíveis nos municípios paraense.

O Brasil caracteriza-se como um país de dimensões continentais, com uma extensão territorial de $8.515 .767,049 \mathrm{~km}^{2}$, formada por uma imensa diversidade de climas, geologia e relevos. Possuindo um contingente populacional de 190.755.799 habitantes, onde 84,36\% concentram- se em áreas urbanas e cerca de $15,64 \%$ em áreas rurais (IBGE, 2010).

Segundo Zoby e Matos (2002) a quantidade de poços existentes no Brasil é de pelo menos 400.000 poços. Fato esse explicado pela alta explotação de águas subterrâneas, para os mais variados fins, tais como abastecimento humano, irrigação, indústria e lazer. De acordo com a Agencia Nacional de Águas (ANA, 2010), atualmente no país, $15,6 \%$ dos domicílios usam exclusivamente águas subterrâneas, cerca de $77,8 \%$ utilizam água provenientes da rede de abastecimento e 6,6\% fazem uso de outras formas de abastecimento. É de suma importância destacar que, dos 77,8\% correspondentes aos domicílios que possuem rede de abastecimento, uma boa parte utiliza água subterrânea.

A utilização dos recursos hídricos subterrâneos, embora seja complementar ao superficial em inúmeras regiões, em outras localidades do país, é visto como o principal manancial hídrico. Desempenhando papel importante no que diz respeito ao desenvolvimento socioeconômico do Brasil (ANA, 2010). Porém, na atualidade é necessário fazer várias considerações ao se adotar essa fonte de água, pois são muitos os processos de contaminação das águas subterrâneas, nas áreas urbanas e rurais, tais como, presença de fossas, oficinas mecânicas, cemitérios, além da disposição inadequada de resíduos urbanos e efluentes de sistemas de esgoto sanitário (Bastos, 2013).

Segundo o Serviço Geológico do Brasil (CPRM, 2013) o Estado do Pará possui seu território dividido em sete domínios Hidrogeológicos: as formações cenozoicas; as bacias sedimentares; o domínio poroso/fissural; as rochas metassedimentares ou metavulcânicas; as rochas vulcânicas; as rochas cristalinas; as rochas carbonáticas e metacarbonáticas. Dentre os domínios mencionado acima, o domínio referente as formações cenozoicas é caracterizadas por aquíferos porosos, com os subdomínios aluviões, e as formações indiferenciadas, Barreiras e Pirabas. Essas duas formações (Pirabas e Barreiras) são as principais fontes responsáveis pelas características das águas subterrâneas dos municípios estudados.

A Formação Pirabas pode ser encontrada ao longo dos estados do Maranhão e Piauí. Possui ocorrências também ao longo da faixa da costa do Pará, nas regiões de Salinópolis, Maracanã, Curuçá 
e nos territórios de Capanema (Matta, Costa e Moraes, 2000). Possui uma litologia caracterizada pela presença de calcário ricamente fossilíferos, apresentando coloração amarelada ou acinzentada, alternados com argilas e areias. Algumas vezes, são caracterizados por calcários duros de coloração cinza, correlacionados com camadas de argila calcífera em leitos sucessivos. Os aquíferos resultantes da Formação Pirabas são considerados os melhores aquíferos da região, uma vez que seus níveis arenosos com grande expressão lateral chegam em torno de $30 \mathrm{~m}$, favorecendo o acúmulo de um grande volume de água, grande transmissividade e com uma vazão em torno de $300.000 \mathrm{~m}^{3} \mathrm{~h}^{-1}$. Suas camadas produtoras são formadas por areias de granulometria fina, média a grossa, algumas com seixos arredondados e subarredondados (CPRM, 2013).

A Formação Barreiras no Estado do Pará tem ocorrência, especialmente, no nordeste brasileiro, na Região Bragantina e nas proximidades da Região Metropolitana de Belém. É um sistema com grande participação no abastecimento nas capitais litorâneas nordestinas de São Luís, Belém, Fortaleza, Natal e Maceió (Matta; Costa; Moraes, 2000; CPRM, 2013). Segundo Almeida (2007), é um aquífero com predominância no município de Abaetetuba. Apresenta uma constituição litológica formada por arenitos, siltitos, argilitos e conglomerados, apresentando cores variadas que estão laterizadas, sob a forma de perfil imaturo (Matta; Costa; Moraes, 2000). Matta et al. (2004) descreve que a unidade Barreiras comumente aparece em profundidades de 25 a 90 metros. Caracterizado com camadas de espessuras em torno de $70 \mathrm{~m} \mathrm{e}$ uma vazão de aproximadamente $80 \mathrm{~m}^{3} \mathrm{~h}^{-1}$.
Neste contexto, o presente trabalho tem por objetivo caracterizar as águas subterrâneas dos aquíferos provenientes das formações Pirabas e Barreiras através de parâmetros físico-químicos e químicos de qualidade da água e aplicação de métodos estatísticos multivariados nos resultados encontrados (quimiometria). Assim como comparar seus resultados com a Portaria $\mathrm{N}^{\mathrm{o}}$ 2914/2011 do Ministério da Saúde e a Resolução No $357 / 2005$ do CONAMA.

\section{Material e métodos}

O presente trabalho foi realizado no Estado do Pará, localizado na região Norte do Brasil. Sendo composto atualmente por 144 municípios (IBGE, 2010). Dos 144 municípios, foram coletadas, analisadas e estudadas as águas subterrâneas, nos municípios de Benevides, Abaetetuba, Barcarena e Capanema.

Inicialmente, foi realizada uma visita prévia nos municípios de Benevides, Barcarena, Abaetetuba e Capanema, com objetivo de selecionar doze residências, em cada município, tendo como critério de seleção casas que utilizassem poços amazonas ou artesianos. Após a seleção, houve um diálogo com os residentes onde foram apresentados os objetivos da pesquisa, e assim, obtida a autorização para realização das coletas. Após a autorização foi feito o levantamento dos pontos amostrais através de um aparelho de GPS (Garmin, GPSMAP ${ }^{\circledR}$, série 78). Na Figura 1 se observa a distribuição dos 12 pontos amostrais em cada um dos quatro municípios estudados, totalizando um total de 48 pontos amostrais. 

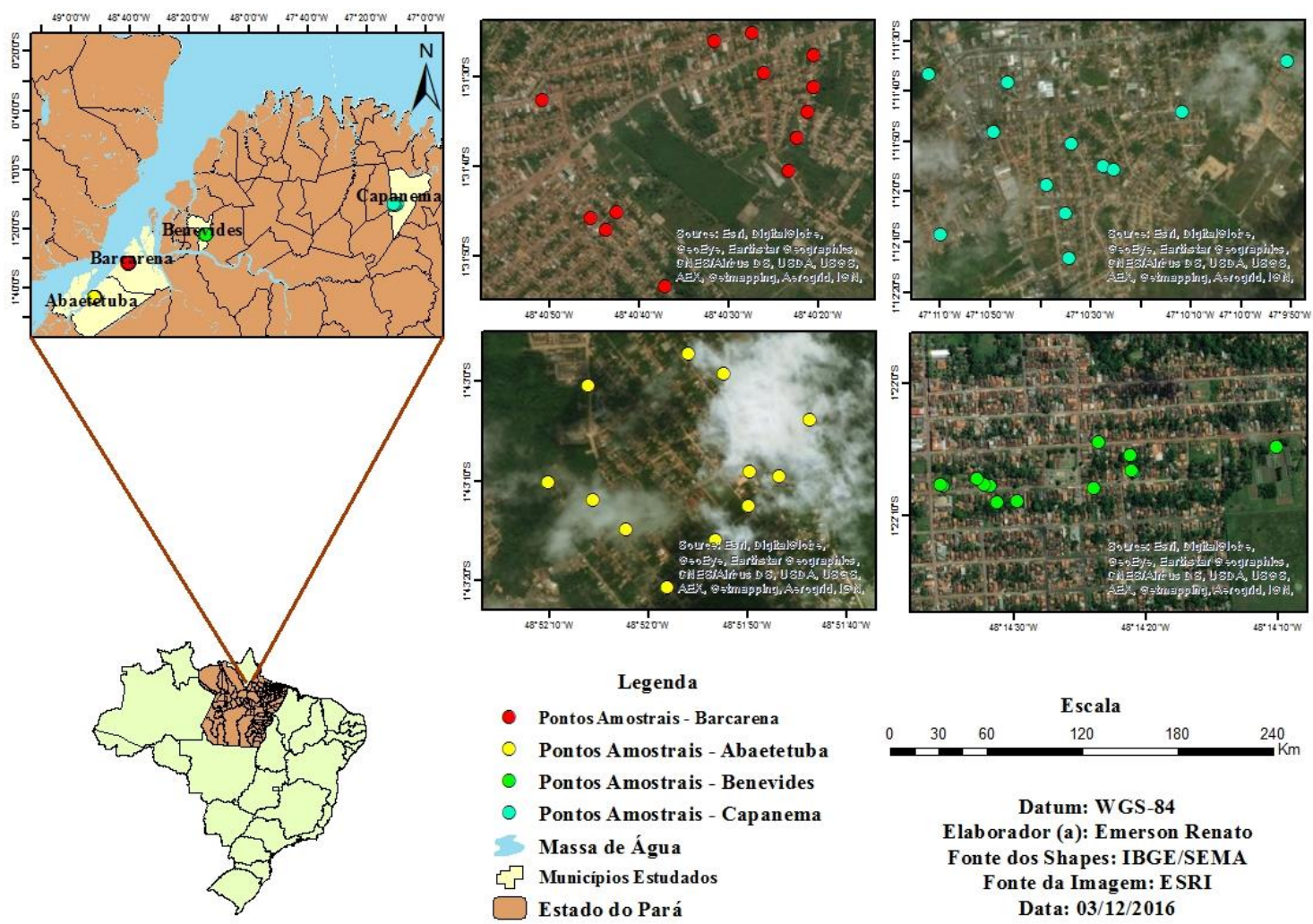

Figura 1. Mapa de localização da área de estudo e dos pontos amostrais.

As coletas foram realizadas no período de março a junho de 2015. A captação da água para as referidas análises foi feita tendo como referência o Guia Nacional de Coleta e Preservação de Amostras (ANA, 2011), o qual instrui coletar amostras diretamente na saída da torneira mais próxima do sistema de captação de água dos poços, se possível diretamente do corpo hídrico. Todas as análises foram feitas em triplicatas. Foram realizadas amostragens de águas para as análises químicas. Para isso as amostras foram armazenadas e identificadas em garrafas de polietileno de $1 \mathrm{~L}$, antecipadamente limpas e esterilizadas (duas garrafas por ponto), e acondicionadas em isopor com gelo até as análises no Laboratório de FísicoQuímica no Centro de Tecnologia Agropecuária (CTA) da Universidade Federal Rural da Amazônia (UFRA).

No local de coleta foram realizadas as medições dos parâmetros físico-químicos: potencial hidrogeniônico $(\mathrm{pH})$, adimensional, aferido em todas as amostras, utilizando-se um peagâmetro de campo, Digital Instrutherm ${ }^{\circledR}$, modelo PH-1900 devidamente calibrado com soluções tampão pH 7,0 e 4,0. A turbidez (Turb) foi determinada utilizando o método nefelométrico, através do uso de um turbidímetro (Instrutherm ${ }^{\circledR}$, modelo TD-300) previamente calibrado com soluções de 0 e 100 NTU. A leitura forneceu os resultados em unidade de turbidez (uT ou NTU). A determinação de oxigênio dissolvido (OD), expressa em $\mathrm{mg} \mathrm{L}^{-1}$ (miligrama por litro), e temperatura (Temp), expressa em ${ }^{\circ} \mathrm{C}$ (graus Celsius), foram determinadas por meio de um oxímetro portátil (Instrutherm $\AA$, modelo MO910), antecipadamente calibrado conforme orientações do fabricante. A determinação da condutividade elétrica (CE), expressa em $\mu \mathrm{S} \mathrm{cm}{ }^{-1}$ (microSiemens por centímetro), foi realizada por meio de um condutivímetro portátil (Instrutherm ${ }^{\circledR}$, modelo CD-850), previamente calibrado com solução padrão de $1413 \mu \mathrm{S} \mathrm{cm}^{-1}$. A determinação dos sólidos totais dissolvidos (STD), expressos em $\mathrm{mg} \mathrm{L}^{-1}$ (miligrama por litro), foi realizada por meio de um medidor portátil de STD (HANNA, modelo HI-98312 DiST®), previamente calibrada.

Para determinação dos parâmetros químicos, determinados em laboratório, foram adotados como referência os procedimentos descritos na $21^{\mathrm{a}}$ edição do Standart Methods for the Examination of Water and Wastewater (APHA, 2005). Assim, a acidez (ACD), expressa em mg de $\mathrm{CaCO}_{3} \mathrm{~L}^{-1}$, foi determinada por meio do método 2310B, que consiste na titulação com indicador, a alcalinidade (ALC), expressa em $\mathrm{mg}$ de $\mathrm{CaCO}_{3} \mathrm{~L}^{-}$ 1 , à qual foi empregado método $2320 \mathrm{~B}$, o teor de cloreto $\left(\mathrm{Cl}^{-}\right)$, expresso em $\mathrm{mg}$ de $\mathrm{Cl}^{-} \mathrm{L}^{-1}$, ao qual foi empregado o método 4500B, volumetria de 
precipitação, o qual também é denominado método de Mohr, a dureza total (DT), expressa em mg L-1 de $\mathrm{CaCO}_{3}$, empregando-se o método $2340 \mathrm{C}$, o teor de cálcio $\left(\mathrm{Ca}^{2+}\right)$, expresso em $\mathrm{mg}$ de $\mathrm{Ca}^{2+} \mathrm{L}^{-1}$, por meio do método 3500-Ca $\mathrm{B}$, e teor de magnésio $\left(\mathrm{Mg}^{2+}\right)$, expresso em $\mathrm{mg}$ de $\mathrm{Mg}^{2+} \mathrm{L}^{-1}$, para o qual não exige procedimento experimental. Sua aferição é dada pela diferença entre os volumes gastos de EDTA na titulação em pH 10 (dureza total) e em pH 12 (teor de cálcio).

\section{Resultados e Discussão}

\section{Caracterização físico-química e química das águas subterrâneas}

A Tabela 1 fornece os valores de médias e desvios padrão gerais (dos doze pontos amostrais) obtidos por meio das determinações in situ, dos parâmetros físico-químicos. Assim como, os Valores Máximos Permitidos (VMP) dispostos pela Portaria no 2914/2011 do Ministério da Saúde (BRASIL, 2011) e a Resolução $n^{\circ} 357 / 2005$ do Conselho Nacional de Meio Ambiente CONAMA (BRASIL, 2005).

Tabela 1. Valores de médias gerais e desvios padrão gerais (Média \pm SD), obtidos por meio das análises in situ.

\begin{tabular}{|c|c|c|c|c|c|c|}
\hline Municípios & pH & $\begin{array}{c}\text { TURB } \\
\text { (uT/NTU) }\end{array}$ & $\begin{array}{c}\text { OD } \\
\left(\mathrm{mg} \mathrm{L}^{-1}\right)\end{array}$ & $\begin{array}{c}\mathrm{CE} \\
\left(\mu \mathrm{S} \mathrm{cm}^{-1}\right)\end{array}$ & $\begin{array}{l}\text { Temp } \\
\left({ }^{\circ} \mathrm{C}\right)\end{array}$ & $\begin{array}{c}\text { STD } \\
\left(\mathrm{mg} \mathrm{L}^{-1}\right)\end{array}$ \\
\hline \multirow{3}{*}{$\mathbf{B E}^{1}$} & $4,04^{\mathrm{b}}$ & $1,56^{\mathrm{a}}$ & $7,08^{\mathrm{a}}$ & $84,92^{\mathrm{a}}$ & $28,03^{b}$ & $75,89^{b}$ \\
\hline & \pm & \pm & \pm & \pm & \pm & \pm \\
\hline & 1,35 & 0,62 & 1,31 & 19,28 & 1,08 & 17,13 \\
\hline \multirow{3}{*}{$\mathbf{A B}^{2}$} & $6,59^{\mathrm{a}}$ & $0,35^{\mathrm{b}}$ & $3,13^{\mathrm{c}}$ & $238,61^{\mathrm{b}}$ & $29,26^{\mathrm{b}}$ & $68,93^{\mathrm{b}}$ \\
\hline & \pm & \pm & \pm & \pm & \pm & \pm \\
\hline & 1,03 & 0,57 & 0,59 & 130,76 & 0,76 & 32,91 \\
\hline \multirow{3}{*}{$\mathbf{B} \mathbf{A}^{3}$} & $4,30^{\mathrm{b}}$ & $0,34^{\mathrm{b}}$ & $7,14^{\mathrm{a}}$ & $213,28^{b}$ & $29,13^{\mathrm{b}}$ & $108,06^{\mathrm{b}}$ \\
\hline & \pm & \pm & \pm & \pm & \pm & \pm \\
\hline & 0,53 & 0,68 & 0,72 & 9,12 & 1,46 & 45,74 \\
\hline \multirow[b]{2}{*}{$\mathrm{CA}^{4}$} & $6,51^{\mathrm{a}}$ & $0,46^{\mathrm{b}}$ & $4,69^{\mathrm{b}}$ & $192,95^{\mathrm{b}}$ & $31,08^{\mathrm{a}}$ & $226,11^{\mathrm{a}}$ \\
\hline & $\begin{array}{c} \pm \\
0,70\end{array}$ & $\begin{array}{c} \pm \\
0,61\end{array}$ & $\begin{array}{c} \pm \\
0,57\end{array}$ & $\begin{array}{c} \pm \\
44,56\end{array}$ & $\begin{array}{c} \pm \\
1,63\end{array}$ & $\begin{array}{c} \pm \\
53,94\end{array}$ \\
\hline VMP* & 6 a 9,5 & $5 \mathrm{uT}$ & - & - & - & $1000 \mathrm{mg} \mathrm{L}^{-1}$ \\
\hline VMP*** & 6 a 9,0 & $40 \mathrm{UNT}$ & $\geq 6 \mathrm{mg} \mathrm{L}^{-1}$ & - & - & $500 \mathrm{mg} \mathrm{L}^{-1}$ \\
\hline
\end{tabular}

Nota: Médias seguidas pela mesma letra, em uma coluna, não apresentam diferença significativa entre si, segundo o teste Tukey (95\%). Os itens com tracejado (-) não são preconizados pela portaria. *VMP: Valores Máximos Permitidos pela Portaria n ${ }^{\circ}$ 2914/2011. **VMP: Valores Máximos Permitidos pela Resolução $n^{\circ}$ 357/2005. ${ }^{1}$ BE: Benevides. ${ }^{2} \mathrm{AB}$ : Abaetetuba. ${ }^{3} \mathrm{BA}$ : Barcarena. ${ }^{4} \mathrm{CA}$ : Capanema.

De acordo com a Análise de Variância (ANOVA), seguida do teste Tukey, os valores de $\mathrm{pH}$, dispostos na Tabela 1, os municípios de Abaetetuba e Capanema não apresentaram diferença significativa entre si. Porém, ambos possuem diferença, quando comparados aos municípios de Benevides e Barcarena, que apresentaram valores baixos de $\mathrm{pH}$.

Segundo Menezes (2012), os baixos valores de $\mathrm{pH}$, podem estar associados a vários fatores, tais como concentrações de $\mathrm{CO}_{2}$, oxidação da matéria orgânica, temperatura da água, entre outros. O que reflete diretamente na diferença significativa dos resultados entre os municípios. Sendo que, os pontos amostrais em Benevides foram todos de poços amazonas, o que favorece a difusão de $\mathrm{CO}_{2}$ no corpo hídrico, favorecendo a diminuição do valor de $\mathrm{pH}$.
Verificou-se que a média geral do $\mathrm{pH}$, referente aos doze pontos analisados, no município de Benevides $(4,04 \pm 1,35)$ e Barcarena $(4,30 \pm 0,53)$, foram os que apresentaram os valores abaixo do estabelecido pela Resolução $\mathrm{n}^{\circ} 357 / 2005$ do CONAMA, para amostras de água doce de Classe 1 (destinada a potabilidade) e Portaria $\mathrm{n}^{\circ}$ 2914/2011 do Ministério da Saúde. Enquanto que, os valores referentes aos municípios de Abaetetuba $(6,59 \pm 1,03)$ e Capanema $(6,51 \pm 0,70)$ encontram-se em concordância com os padrões vigentes nas legislações que é de 6 a 9,5.

$\mathrm{O}$ pH influencia na qualidade da água, uma vez que, quando apresentam valores baixos as águas tornam-se mais corrosivas. Porém, quando apresentam valores elevados há possibilidade de surgimento de incrustações nas canalizações de

Silva, E. R. M., Costa, L. G. S., Silva, A. S., Souza, E. C., Barbosa, I. C. C. 
distribuição, normalmente utilizadas em poços artesianos (Fernandes, 2011).

Observando a Tabela 1, quanto à turbidez, verificou-se que de acordo com a ANOVA, seguida do teste de Tukey, as amostras de Barcarena, Abaetetuba e Capanema não apresentam diferenças significativas entre si. Porém, diferenciam-se significativamente das amostras de Benevides. Essa igualdade significativa entre as amostras de Barcarena, Abaetetuba e Capanema, segundo Feitosa e Filho (2000), está associada ao efeito de filtro que o solo desempenha, fazendo com que as águas subterrâneas apresentem geralmente valores baixos de turbidez. Assim as águas dos municípios de Benevides, Abaetetuba, Barcarena e Capanema encontram-se dentro do padrão de potabilidade preconizado pela Portaria $\mathrm{n}^{\mathrm{o}} 2914 / 2011$ e a Resolução no 357/2005.

Quanto ao oxigênio dissolvido, por meio da ANOVA, seguida do teste de Tukey, observa-se que as amostras dos municípios de Benevides e Barcarena apresentaram semelhança entre si. Enquanto que, Abaetetuba e Capanema, além de apresentarem diferença significativas entre si, também diferem significativamente de Benevides e Barcarena.

As concentrações de oxigênio dissolvido, presentes na Tabela 1, apresentaram uma variação de $3,13 \mathrm{mg} \mathrm{L}^{-1} \mathrm{em}$ Abaetetuba a 7,14 $\mathrm{mg} \mathrm{L}^{-1} \mathrm{em}$ Barcarena. A Portaria ${ }^{\circ} 2914 / 2011$, do Ministério da Saúde, não estabelece valores padrões para este parâmetro. Porém, de acordo com a Resolução $\mathrm{n}^{\circ}$ $357 / 2005$ do CONAMA, as amostras de água doce, para serem classificadas como de Classe 1 (destinada a potabilidade) não podem apresentar concentrações inferiores a $6 \mathrm{mg} \mathrm{L}^{-1}$. Dessa forma, as amostras de água dos municípios de Benevides e Barcarena encontram-se em conformidade com o estabelecido pela Portaria ${ }^{\circ}$ 357/2005. Enquanto que, as amostras dos municípios de Abaetetuba e Capanema apresentaram concentrações abaixo do valor preconizado pela legislação.

As concentrações baixas de oxigênio dissolvido, segundo Janzen, Schultz e Lamon (2008), estão associadas ao consumo de oxigênio por meio da decomposição da matéria orgânica ou pela respiração realizada por microrganismos.

Quanto à condutividade elétrica, observase que por meio da ANOVA, seguida do teste de Tukey, as amostras dos municípios de Abaetetuba, Barcarena e Capanema não apresentaram diferença significativa entre si. Porém diferem significativamente das amostras do município de Benevides.

A condutividade variou de $84,92 \mu \mathrm{S} \mathrm{cm} \mathrm{cm}^{-1}$ em Benevides a 238,61 $\mu \mathrm{S} \mathrm{cm}^{-1}$ em Abaetetuba.
Valores elevados de condutividade elétrica foram registrados em Abaetetuba e Barcarena o que está associado ao tipo de solo predominante na região que é o Latossolo Amarelo Distrófico. Esse solo ocorre de forma predominante sobre sedimentos da Formação Barreiras e possui uma alta capacidade de troca iônica, o que favorece a elevação nos valores de condutividades das águas deste aquífero nos municípios (Almeida, 2007; CDP, 2016). Apenas em alguns países são determinados limites de aceitação para a condutividade elétrica, variando de $250 \mu \mathrm{S} \mathrm{cm}^{-1}$ (ANZECC, 2000) a 500 $\mu \mathrm{S} \mathrm{cm}^{-1}$ (KPDES, 2010).

A determinação da condutividade elétrica é importante, pois o valor de sua concentração serve como indicador da avaliação de mineralização da água (Feitosa e Filho, 2000). Assim como, a representação indireta da concentração de poluentes no corpo hídrico (CETESB, 2009; BRASIL, 2014).

Quanto aos resultados de temperatura obtidos nos quatro municípios, por meio da ANOVA, seguida do teste de Tukey, Benevides apresenta uma similaridade com Abaetetuba e Barcarena. Porém, ambos diferem significativamente de Capanema que apresentou o maior valor de temperatura.

A temperatura teve uma variação de 28,03 ${ }^{\circ} \mathrm{C}$ em Benevides a $31,08{ }^{\circ} \mathrm{C}$ em Capanema. Segundo Menezes (2012), a temperatura de águas subterrâneas em poços mais profundos é menor do que em poços mais rasos. Porém, essa variação na estratificação vertical, ou seja, profundidade de captação da água não foi o fator responsável pela variação dos resultados. Pois, as águas analisadas de Benevides, Abaetetuba e Barcarena são provenientes do aquífero Barreiras que possui profundidade de captação em torno de 25 a $90 \mathrm{~m}$. Enquanto, o município de Capanema é constituído por aquífero da Formação Pirabas, com profundidades em torne de 180 a $200 \mathrm{~m}$ (Almeida, 2007; CPRM, 2013). Dessa maneira, as amostras do município de Capanema apresentaram as maiores temperaturas, não estando de acordo com Menezes (2012).

Assim, a similaridade e dissimilaridade podem ser explicadas pela diferença das águas de cada aquífero. Já a variação nos valores obtidos, é explicada pelas condições climáticas do ambiente no período das determinações. Em Benevides estava ocorrendo precipitação no dia da análise. Em Abaetetuba e Barcarena foram feitas análises no período da manhã. Enquanto que, em Capanema foram feitas análises no período da tarde, no momento de maior incidência solar. Fatores que 
podem explicar a variação nos valores de temperatura em cada município.

De acordo com os resultados encontrados de STD, por meio da ANOVA, seguida do teste de Tukey, observou-se uma semelhança significativa entre as amostras dos municípios de Benevides, Abaetetuba e Barcarena. Por outro lado, as amostras do município de Capanema, apresentou diferença significativa com as demais amostras.

Nenhuma das amostras analisadas apresentou-se em desconformidade ao valor máximo de $1000 \mathrm{mg} \mathrm{L}^{-1}$ estabelecido pela Portaria

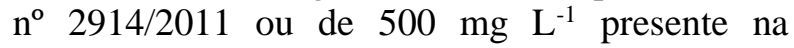
Resolução no 357/2005 para águas destinadas ao consumo. Sendo que, as amostras provenientes da formação Barreiras, por terem uma profundidade de captação menor, podem apresentam um menor tempo de contato com as rochas, podendo resultar em menores concentrações de STD que as amostras do aquífero proveniente da formação Pirabas em Capanema. As concentrações de sólidos totais dissolvidos (STD) em águas subterrâneas são muito superiores as de águas superficiais, devido ao contato prolongado com as rochas, conhecido como tempo de residência. (Menezes, 2012).

A Tabela 2 fornece os valores de médias e desvios padrão gerais (dos doze pontos amostrais), obtidos por meio das análises laboratoriais. Assim como, os Valores Máximos Permitidos (VMP) dispostos pela Portaria n ${ }^{\circ}$ 2914/2011 do Ministério da Saúde (BRASIL, 2011) e a Resolução $\mathrm{n}^{\circ}$ 357/2005 do Conselho Nacional de Meio Ambiente - CONAMA (BRASIL, 2005).

Tabela 2. Valores de médias gerais e desvios padrão gerais (Média \pm SD), obtidos por meio das análises laboratoriais.

\begin{tabular}{|c|c|c|c|c|c|c|}
\hline Municípios & 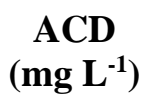 & $\begin{array}{r}\mathrm{ALC} \\
\left(\mathrm{mg} \mathbf{L}^{-1}\right)\end{array}$ & $\begin{array}{c}\mathrm{Cl}^{-} \\
\left(\mathrm{mg} \mathrm{L}^{-1}\right)\end{array}$ & $\begin{array}{c}\text { DT } \\
\left(\mathrm{mg} \mathrm{L}^{-1}\right)\end{array}$ & $\begin{array}{c}\mathrm{Ca}^{2+} \\
\left(\mathrm{mg} \mathrm{L}^{-1}\right)\end{array}$ & $\begin{array}{c}\mathrm{Mg}^{2+} \\
\left(\mathrm{mg} \mathrm{L}^{-1}\right)\end{array}$ \\
\hline \multirow{3}{*}{$\mathbf{B E}^{1}$} & $39,06^{\mathrm{a}}$ & $5,77^{b}$ & $24,35^{\mathrm{b}}$ & $21,68^{b}$ & $5,35^{\mathrm{b}}$ & $1,46^{\mathrm{b}}$ \\
\hline & \pm & \pm & \pm & \pm & \pm & \pm \\
\hline & 14,49 & 3,69 & 4,13 & 19,11 & 4,00 & 1,70 \\
\hline \multirow{3}{*}{$\mathbf{A B}^{2}$} & $23,28^{a}$ & $4,72^{b}$ & $36,20^{b}$ & $6,03^{b}$ & $1,40^{\mathrm{b}}$ & $0,57^{b}$ \\
\hline & \pm & \pm & \pm & \pm & \pm & \pm \\
\hline & 9,09 & 0,87 & 10,49 & 2,40 & 0,71 & 0,44 \\
\hline \multirow{3}{*}{$\mathbf{B A}^{3}$} & $28,87^{\mathrm{a}}$ & $7,33^{b}$ & $29,34^{b}$ & $20,08^{b}$ & $5,61^{b}$ & $1,42^{b}$ \\
\hline & \pm & \pm & \pm & \pm & \pm & \pm \\
\hline & 11,46 & 3,30 & 10,71 & 9,72 & 3,04 & 0,71 \\
\hline \multirow{3}{*}{$\mathrm{CA}^{4}$} & $36,36^{\mathrm{a}}$ & $143,56^{\mathrm{a}}$ & $60,13^{a}$ & $198,10^{\mathrm{a}}$ & $69,83^{a}$ & $3,59^{a}$ \\
\hline & \pm & \pm & \pm & \pm & \pm & \pm \\
\hline & 20,80 & 108,03 & 17,24 & 86,25 & 32,22 & 3,24 \\
\hline VMP* & - & - & $250 \mathrm{mg} \mathrm{L}^{-1}$ & $500 \mathrm{mg} \mathrm{L}^{-1}$ & - & - \\
\hline VMP** & - & - & $250 \mathrm{mg} \mathrm{L}^{-1}$ & - & - & - \\
\hline
\end{tabular}

Nota: Médias seguidas pela mesma letra, em uma coluna, não apresentam diferença significativa entre si, segundo o teste Tukey $(95 \%)$. Os itens com tracejado (-) não são preconizados pela portaria. *VMP: Valores Máximos Permitidos pela Portaria $n^{\circ}$ 2914/2011. **VMP: Valores Máximos Permitidos pela Resolução n ${ }^{\circ}$ 357/2005. ${ }^{1}$ BE: Benevides. ${ }^{2} A B$ : Abaetetuba. ${ }^{3} \mathrm{BA}$ : Barcarena. ${ }^{4} \mathrm{CA}$ : Capanema.

De acordo com os resultados de acidez, mesmo sendo amostras de águas provenientes de aquíferos diferentes, observa-se que, por meio da ANOVA, seguida do teste de Tukey, não apresentaram diferença significativas entre si. As legislações utilizadas no presente trabalho não estabelecem valores máximos permitidos para acidez.

A acidez para os pontos amostrais teve uma variação de $23,28 \mathrm{mg} \mathrm{L}^{-1} \mathrm{em}$ Abaetetuba a $39,06 \mathrm{mg} \mathrm{L}^{-1} \mathrm{em}$ Benevides. Associada ao baixo valor de $\mathrm{pH}$ obtido nas amostras de Benevides, observa-se que as águas com maiores concentrações de acidez foram as do município de Benevides. De acordo com Santos (2008), a determinação da acidez é importante, pois contribui para indicação de lançamento de esgotos e percolado líquido contaminado em ambientes hídricos naturais.

Para os resultados de alcalinidade das amostras estudadas, observa-se por meio da ANOVA, seguida do teste de Tukey, que as águas dos municípios de Benevides, Abaetetuba e Barcarena não apresentaram diferença significativa

Silva, E. R. M., Costa, L. G. S., Silva, A. S., Souza, E. C., Barbosa, I. C. C. 
entre suas amostras. Enquanto que, as amostras de água do município de Capanema diferem significativamente dos demais municípios. Diferença resultante da litologia da formação Pirabas, presente no município de Capanema, que possui como características a presença de calcário, promovendo às águas do aquífero da região uma alcalinidade maior que nas amostras de águas da formação Barreiras.

As concentrações de alcalinidade das amostras analisadas, dispostas na Tabela 2, variaram de 4,72 $\mathrm{mg} \mathrm{L}^{-1} \mathrm{em}$ Abaetetuba a 143,56 $\mathrm{mg} \mathrm{L}^{-1}$ em Capanema. Alencar (2007) aborda que concentrações elevadas de alcalinidade, como as obtidas em Capanema, são resultantes de águas que percolam rochas calcárias. A Portaria $\mathrm{n}^{\circ}$ 2914/2011 e a Resolução $n^{\circ}$ 357/2005 do CONAMA não estabelecem valores máximos permitidos para este parâmetro. Porém, de acordo com o Guia de Boas Práticas no Abastecimento de Águas do Ministério da Saúde (BRASIL, 2006), água destinada ao consumo humano deve ser tratada para apresentar alcalinidade igual a $50 \mathrm{mg} \mathrm{L}^{-1}$ e no mínimo $35 \mathrm{mg}$ $\mathrm{L}^{-1}$. Assim, as amostras de Capanema encontramse em desconformidade quanto aos valores descritos para consumo humano. Enquanto que, as águas de Benevides, Abaetetuba e Barcarena atendem as exigências do Guia de Boas Práticas no Abastecimento de Água do Ministério da Saúde (BRASIL, 2006).

Com relação aos resultados das concentrações de cloreto, por meio da ANOVA, seguida do teste de Tukey, observou-se que Capanema foi o município onde as amostras de água apresentaram diferenças significativas em relação aos demais. Alencar (2007) descreve que as concentrações de cloreto tendem a elevar-se a partir das zonas de recarga das águas subterrâneas. O que explica a diferença conferida ao município de Capanema em relação aos demais, pois possui uma zona de recarga superior as dos municípios de Benevides, Abaetetuba e Barcarena.

As concentrações de cloreto, apresentadas na Tabela 2, tiveram uma variação de $24,35 \mathrm{mg} \mathrm{L}^{-}$ ${ }^{1} \mathrm{em}$ Benevides a $60,13 \mathrm{mg} \mathrm{L}^{-1} \mathrm{em}$ Capanema. Quanto ao uso para consumo humano, as águas de todos os municípios, apresentam-se dentro dos padrões de aceitabilidade para consumo humano segundo a Portaria 2914/2011 e a Resolução $n^{\circ}$ $357 / 2005$ que é de $250 \mathrm{mg} \mathrm{L}^{-1}$. Em águas para consumo humano, sua influência está diretamente associada a alterações no sabor. Os cloretos de sódio, de potássio e de cálcio, quando em concentrações acima de 200 a 300 mg L ${ }^{-1}$, são os principais responsáveis pela alteração no sabor da água (BRASIL, 2006). Pois, quando em concentrações elevadas, conferem sabor salgado na água, assim como, propriedades laxativas, levando a rejeição pelo consumidor (BRASIL, 2014).

Por meio da ANOVA, seguida do teste de Tukey, para os resultados de dureza total, observase uma igualdade significativa entre as amostras de Benevides, Abaetetuba e Barcarena. E por serem amostras de águas do aquífero proveniente da formação Pirabas, as amostras de Capanema diferem significativamente dos demais municípios. A litologia da formação Pirabas, é o fator principal para tal diferenciação, por apresentar calcário em teores elevados (CPRM, 2013).

Por sua vez, as concentrações obtidas na análise de dureza total, dispostas na Tabela 2 , oscilaram de $6,03 \mathrm{mg} \mathrm{L}^{-1}$ no município de Abaetetuba a $198,10 \mathrm{mg} \mathrm{L}^{-1}$ em Capanema. A Portaria $n^{\circ}$ 2914/2011 do Ministério da Saúde estabelece como valor máximo permitido para consumo $500 \mathrm{mg} \mathrm{L}^{-1}$. Assim, quanto à potabilidade, as amostras de todos os municípios, encontram-se de acordo com o padrão estabelecido para consumo.

Quanto ao nível de concentração da dureza, as águas podem apresentar dureza branda, concentrações menores que $50 \mathrm{mg} \mathrm{L}^{-1} \mathrm{de}_{\mathrm{CaCO}_{3}}$; pouco dura, concentrações entre 50 e $100 \mathrm{mg} \mathrm{L}^{-1}$ de $\mathrm{CaCO}_{3}$; dura, com concentrações entre 100 e 200 $\mathrm{mg} \mathrm{L}^{-1}$ de $\mathrm{CaCO}_{3}$; e muito dura, com concentrações maiores que $200 \mathrm{mg} \mathrm{L}^{-1}$ de $\mathrm{CaCO}_{3}$ (Custódio e Llamas, 1983).

Quanto a classificação da dureza, para as amostras de água analisadas, as águas dos municípios de Benevides, Abaetetuba e Barcarena apresentaram concentrações abaixo de $50 \mathrm{mg} \mathrm{L}^{-1}$ de $\mathrm{CaCO}_{3}$, caracterizando-as como águas de dureza branda. Por outro lado, as amostras de água de Capanema, de acordo com a média geral, enquadram-se na classificação de águas duras (concentrações entre 100 a $200 \mathrm{mg} \mathrm{L}^{-1}$ de $\mathrm{CaCO}_{3}$ ), o que resulta em restrições quanto ao seu uso, principalmente industriais, sendo necessário o tratamento prévio destas águas (Abdalla et al., 2010).

Quanto aos resultados das concentrações de cálcio e magnésio, por meio da ANOVA, seguida do teste de Tukey, as amostras dos municípios de Benevides, Abaetetuba e Barcarena não apresentaram diferenças significativas entre si.

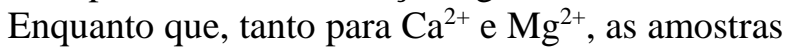
de Capanema diferem significativamente em relação às amostras dos outros municípios.

Os teores dos íons de cálcio $\left(\mathrm{Ca}^{2+}\right)$ oscilaram entre um mínimo de $1,40 \mathrm{mg} \mathrm{L}^{-1} \mathrm{em}$ Abaetetuba e um máximo de $69,83 \mathrm{mg} \mathrm{L}^{-1} \mathrm{em}$ Capanema. Para os íons de magnésio $\left(\mathrm{Mg}^{2+}\right)$ as 
concentrações variaram entre $0,57 \mathrm{mg} \mathrm{L}^{-1} \mathrm{em}$ Abaetetuba e 3,59 mg $\mathrm{L}^{-1}$ em Capanema. As legislações usadas como padrão de potabilidade neste trabalho não estabelecem valores máximos para o referido fim. Porém, as concentrações de

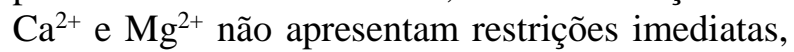
uma vez que, possuem propriedades favoráveis à saúde humana e vegetal, além de serem considerados minerais principais, ou macronutrientes, de vital importância para a vida (Alvarenga, 2001), e propriedades fundamentais para o desenvolvimento das plantas, associadas às funções estruturais (Dias, Neves e Silveira, 2012).

\section{Análise multivariada (PCA e HCA)}

Como nem todos os parâmetros apresentaram diferenças significativas entre si (por meio da ANOVA, seguida do teste de Tukey), os resultados dos parâmetros turbidez, acidez, cálcio e magnésio, não foram submetidos à Análise Multivariada. Vale ressaltar que, o cálcio e magnésio, foram retirados por serem os responsáveis pela dureza da água, logo apresentam influência similar ao do parâmetro dureza total. Dessa forma, foi efetuada uma análise de componentes principais, por meio do software
Minitab $16.0^{\circledR}$, com objetivo principal a redução da dimensionalidade do conjunto de dados, sem comprometer os dados originais, conservando o máximo de informações possível (Carvalho et al., 2015).

Com intuito de selecionar as componentes principais que contribuíram de forma mais significativa para a explicação da variação dos dados, Reis (1997) descreve que existem vários critérios para determinar quais componentes devem ser excluídas da análise. Dentre os critérios mais utilizados na literatura temos o critério 1 , que leva em consideração a proporção da variância explicada por cada componente principal. Assim, selecionam-se as componentes que resultem numa proporção de variância acumulada superior a $70 \%$. $\mathrm{O}$ critério 2 é definido como critério de Kaise e sugere que deve-se reter as componentes principais que apresentem autovalores superiores a um. Enquanto que, o critério 3 é definido de Scree plot e foi proposto por Cattell em 1966. O critério descreve que devem reter as componentes principais que antecedem o momento em que o declive atenua, ou seja, quando os valores próprios forem próximos entre si e de zero.

Observa-se na Tabela 3 a projeção dos dados em um espaço com 8 dimensões, ou seja, oito componentes principais.

Tabela 3. Autovalores, proporção da variância explicada e variância acumulada para cada componente principal.

\begin{tabular}{lccc}
\hline \hline PCs & Autovalores & $\begin{array}{c}\text { Variância } \\
\text { explicada (\%) }\end{array}$ & $\begin{array}{c}\text { Variância } \\
\text { acumulada (\%) }\end{array}$ \\
\hline PC1 & 3,976 & 49,7 & 49,7 \\
PC2 & 1,295 & 16,2 & 65,9 \\
PC3 & 1,209 & 15,1 & 81,0 \\
PC4 & 0,671 & 8,4 & 89,4 \\
PC5 & 0,456 & 5,7 & 95,1 \\
PC6 & 0,267 & 3,3 & 98,4 \\
PC7 & 0,089 & 1,1 & 99,6 \\
PC8 & 0,034 & 0,4 & 100 \\
\hline \hline
\end{tabular}

De acordo com o critério 1 e critério 2 , observa-se na Tabela 3 que apenas as três componentes iniciais (PC1: 49,7\%, PC2: 16,2\%, PC3: $15,1 \%$ ) foram as mais significativas na explicação das variações dos dados, e as únicas com autovalores superiores a um. O que totaliza uma variância acumulada de aproximadamente $81 \%$ dessa variação.

Na Figura 2, temos a projeção do gráfico Scree plot (critério 3). Esse gráfico é plotado com base nos autovalores da Tabela 3, o que reforça a seleção das componentes principais mais significativas, PC1, PC2 e PC3. 


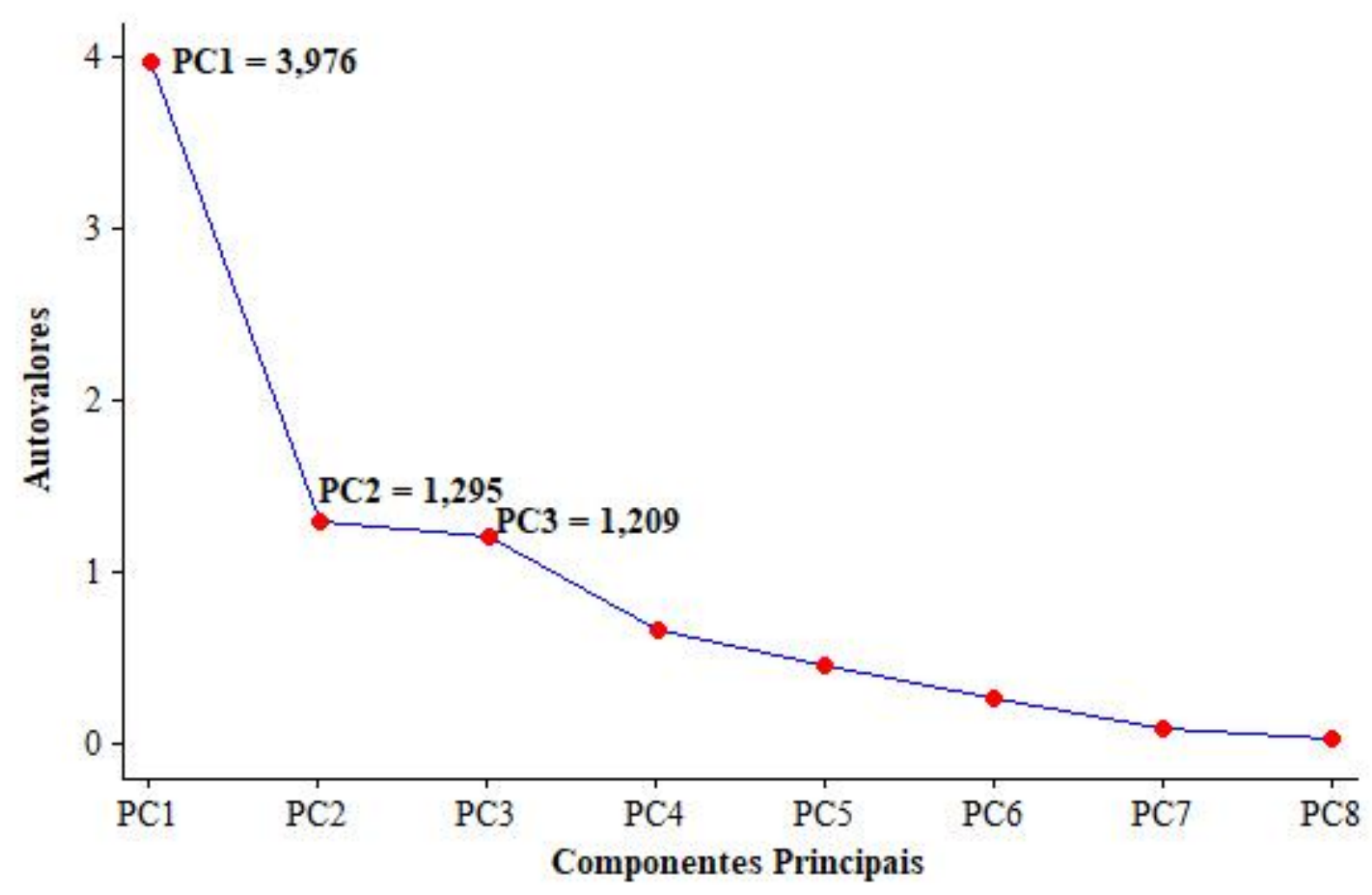

Figura 2. Gráfico de Scree plot, destacando os autovalores das componentes principais mais significativas.

Observa-se no gráfico da Figura 2 que a partir da componente principal PC4 os autovalores começam a aproximar-se do zero. Assim as componentes principais de PC4 à PC8 não apresentam explicações significativas para variação dos dados.

Uma vez determinadas as componentes principais mais significativas, a análise de componentes principais realiza a projeção do gráfico de scores (Figura 3), por meio de uma projeção bidimensional entre a PC1, que explicou 49,7\% da variância dos dados, e a PC2 que explicou $16,2 \%$ da variância dos dados, o que totaliza numa explicação de aproximadamente 65,9\% da variância dos dados (PC1 x PC2). 


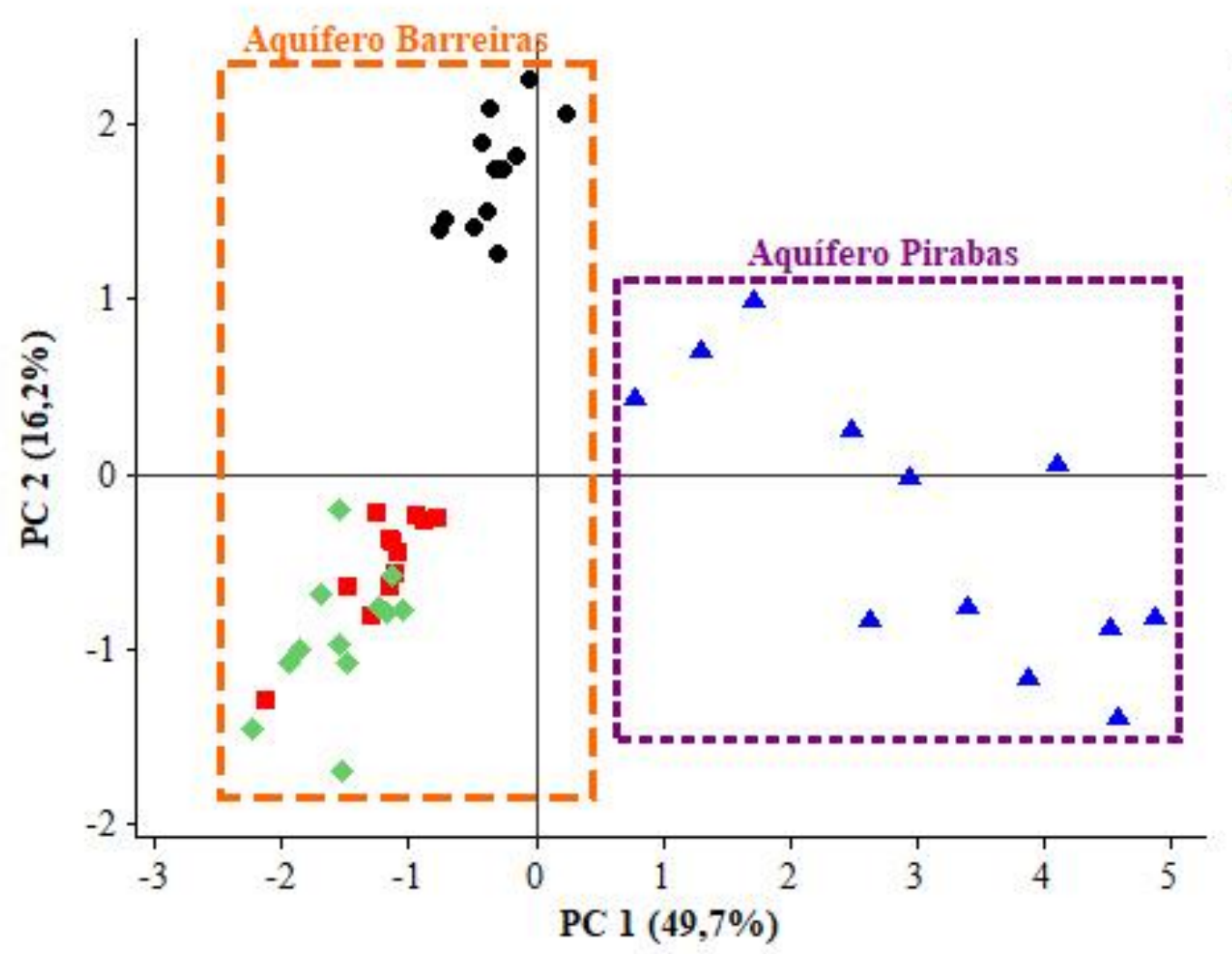

Figura 3. Gráfico de scores PC1 x PC2 correspondente às amostras de águas subterrâneas estudadas dos municípios paraense, Benevides, Abaetetuba, Barcarena e Capanema.

A análise do gráfico de scores revela de forma nítida, por meio da PC1, a separação entre o grupo com as amostras de água proveniente da formação Barreiras, formado pelas amostras dos municípios de Benevides, Abaetetuba e Barcarena, dispostos na extremidade negativa da PC1. E a formação do grupo como amostras de água provenientes da formação Pirabas das amostras do município de Capanema, distribuídos na extremidade positiva da PC1. Comprovando a hipótese de que as características de cada formação, dada as suas condições litológicas, promovem a discriminação das amostras segundo o município e as propriedades químicas das águas subterrâneas.

Ainda no gráfico de scores, agora observando a PC2, é possível visualizar o distanciamento das amostras do município de Abaetetuba, disposto na extremidade positiva da PC2, dos demais pontos amostrais de Benevides e Barcarena, distribuídos na extremidade negativa da PC2. Comportamento que mostra uma diferenciação entre as amostras oriundas da mesma formação, ou seja, diferenças provenientes das propriedades químicas distintas dos corpos hídricos de cada município.

O gráfico de loadings (Figura 4) favorece a explicação e o entendimento de quais variáveis (parâmetros), utilizadas na análise de componentes principais, mais contribuíram para a separação e formação dos grupos apresentados no gráfico de scores (Figura 3). 


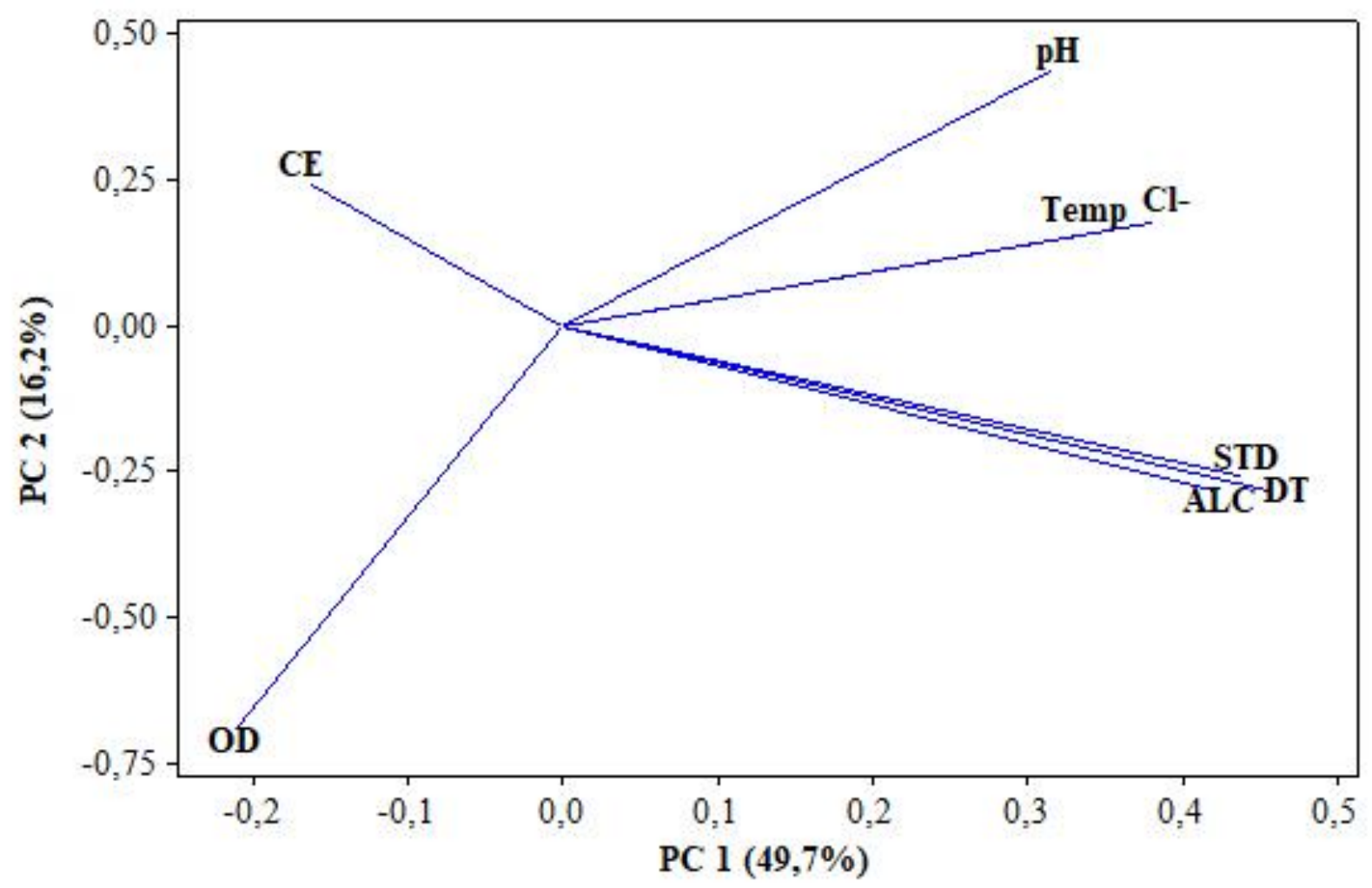

Figura 4. Gráfico de loadings correspondentes aos parâmetros estudados nas amostras de águas subterrâneas dos municípios Benevides, Abaetetuba, Barcarena e Capanema: PC1 x PC2.

Partindo da observação do comportamento dos parâmetros, de acordo com a PC1 e PC2, verifica-se que no eixo da PC1, em sua extremidade positiva, os parâmetros alcalinidade (ALC), dureza total (DT), sólidos totais dissolvidos (STD), temperatura (Temp), cloreto $\left(\mathrm{Cl}^{-}\right)$e potencial hidrogeniônico $(\mathrm{pH})$, foram os parâmetros responsáveis pela discriminação e formação do grupo com as amostras provenientes da formação Pirabas. Uma vez que, ao analisar a Tabela 1, observa-se que, com exceção do pH, a temperatura e os STD nas amostras de Capanema, diferenciaram-se significativamente das amostras dos demais municípios, pelas características litológicas da formação Pirabas.

Quanto aos resultados dispostos na Tabela 2 , verificou-se que, exceto a acidez, os demais parâmetros, entre eles cloreto, dureza total e alcalinidade, nas amostras de Capanema, sofreram grandes influências da litologia da formação Pirabas. Essa influência resultou em maiores concentrações nas amostras de águas provenientes do Aquífero Pirabas, resultando na diferenciação significativa desses parâmetros dos demais municípios.

Ainda no gráfico de loadings, na extremidade negativa da $\mathrm{PC} 1$, verifica-se que o oxigênio dissolvido (OD) e a condutividade elétrica (CE), foram os parâmetros que contribuíram para a formação do grupo formação Barreiras. Ao se analisar o gráfico de loadings, de acordo com a PC2, é possível obter a explicação para o comportamento das amostras do grupo formação Barreiras. Pois, verifica-se que na extremidade negativa, o oxigênio dissolvido (OD) foi a variável que contribuiu para a separação das amostras dos municípios de Benevides e Barcarena das amostras de Abaetetuba. E ao verificar na Tabela 1, a contração de OD nas amostras de Benevides e Barcarena, além de apresentarem semelhança significativa entre si, apresentaram os maiores valores de concentração. Explicando assim a união entre os seus pontos amostrais no gráfico de scores (Figura 3).

Observando para a extremidade positiva da PC2, no gráfico de loadings, é notório que a condutividade elétrica (CE) foi o parâmetro responsável pelo deslocamento e separação das amostras do município de Abaetetuba das demais amostras dos municípios do grupo formação Barreiras. Pois, na Tabela 1, a concentração da condutividade elétrica foram maiores nas amostras de Abaetetuba. Conforme já mencionado anteriormente, esse valor elevado é explicado por 
meio da característica dos solos dessa região que apresentam alta capacidade de troca iônica, favorecendo o aumento da condutividade elétrica.

Os resultados obtidos por meio da associação entre as variáveis físico-químicas e químicas e amostras observados na projeção das componentes principais PC1 x PC2, são confirmados na Análise Hierárquica de Agrupamento (HCA). Empregando-se a padronização dos dados, ligações completas e distância Euclidiana, obteve-se o dendrograma dado na Figura 5. No dendrograma da Figura 5, as linhas na vertical representam as amostras dos municípios estudados, e as linhas nas horizontais representam as medidas de similaridades calculadas por meio das distâncias Euclidianas, as quais são responsáveis pela formação dos agrupamentos entre as amostras.

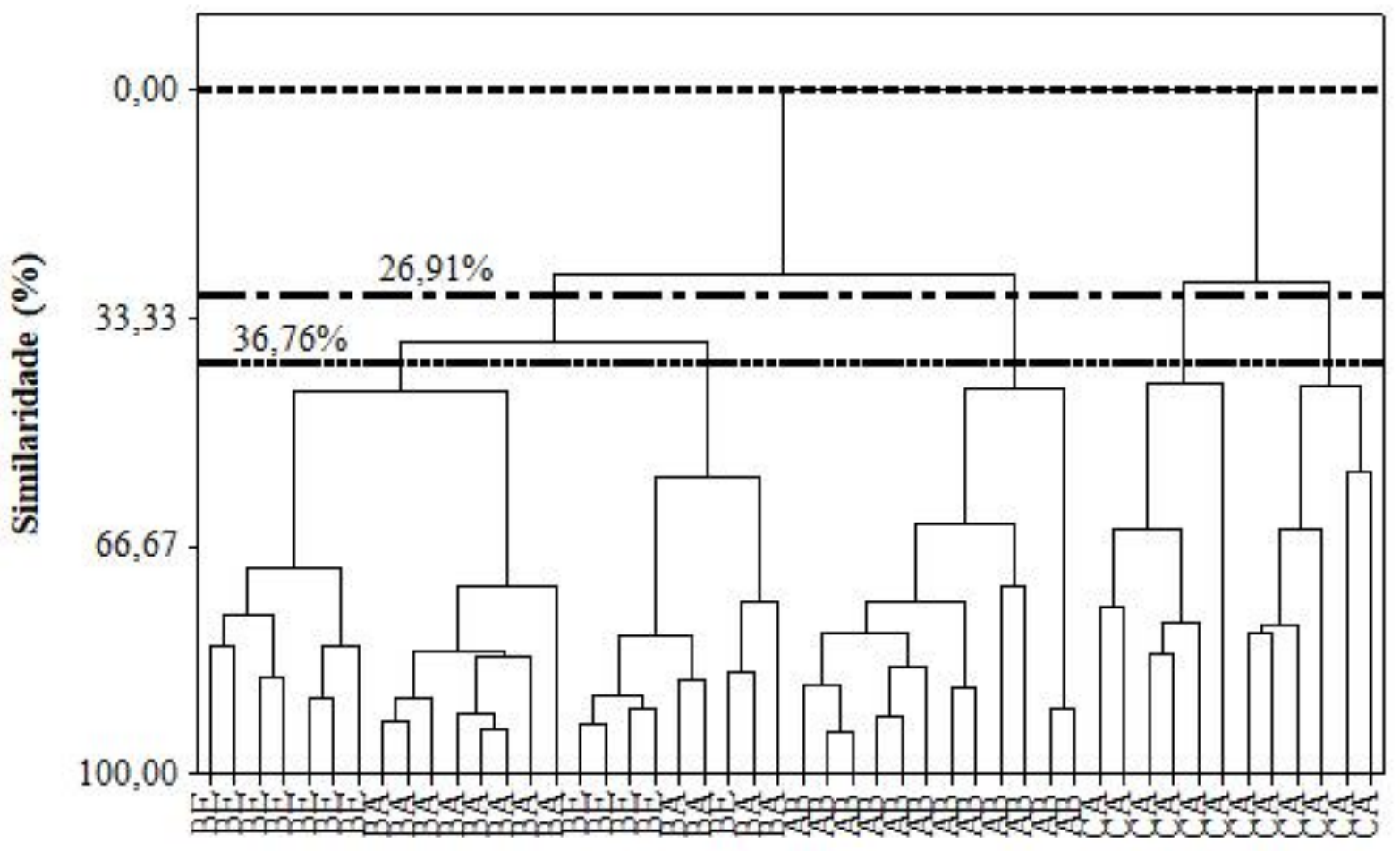

\section{Municípios}

Figura 5. Dendrograma para as análises físico-químicas e químicas das amostras de águas dos municípios Benevides, Abaetetuba, Barcarena e Capanema.

Ao analisar o dendrograma, observa-se que o mesmo proporcionou a separação dos grupos de acordo com as amostras dos quatro municípios estudados. Sendo que, inicialmente, observa-se a máxima dissimilaridade $(0,00 \%)$ entre as amostras do município de Capanema (formação Pirabas) com as amostras dos municípios de Benevides, Abaetetuba e Barcarena (formação Barreiras).

Ao fazer a análise da esquerda para a direita, observa-se o agrupamento das amostras dos municípios de Benevides, Abaetetuba e Barcarena. Apesar das amostras de Abaetetuba se distanciarem das demais amostras da formação Barreiras, essas amostras apresentam uma similaridade de aproximadamente $26,91 \%$. Por outro lado, é evidente uma maior similaridade entre as amostras dos municípios de Benevides e Barcarena levando à formação de um grupo não homogêneo, mencionada anteriormente pelos valores elevados de oxigênio dissolvido. Apresenta assim, uma similaridade de aproximadamente $36,76 \%$.

\section{Conclusões}

De acordo com os resultados obtidos por meio das análises físico-químicas e químicas, assim como a aplicação da ANOVA, seguida do teste de Tukey e da estatística multivariada, foi possível caracterizar as águas subterrâneas dos aquíferos Pirabas e Barreiras. Pois, foi observado que as amostras de água dos dois aquíferos apresentaram uma diferença significativa entre si, por meio dos parâmetros: oxigênio dissolvido, potencial hidrogeniônico, condutividade elétrica, temperatura, cloreto, sólidos totais dissolvidos, alcalinidade, dureza total, teores de cálcio e 
magnésio, resultando na discriminação de dois grupos distintos, formados por amostras dos aquíferos Pirabas e Barreiras.

A caracterização das águas subterrâneas pode ter sofrido influência das características geográficas de cada município e, as peculiaridades dos principais aquíferos, tais como, o tipo de solo predominante em cada região, a profundidade de captação para cada um dos principais aquíferos, entre outras características.

Quanto à potabilidade das amostras, de acordo com as referidas legislações, o potencial hidrogeniônico, turbidez, alcalinidade e oxigênio dissolvido não atenderam as exigências para

\section{Referências}

Abdalla, K.V.P., Cavalcante, P.R.S., Neto, J.P.C., Barbieri, R., Neto, M.C.M., 2010. Avaliação da Dureza e das Concentrações de Cálcio e Magnésio em Águas Subterrâneas da Zona Urbana e Rural do Município de Rosário-MA. Disponível:

https://aguassubterraneas.abas.org/asubterranea s/article/view/22915/15056. Acesso: 05 jan. 2017.

Alencar, A. A., 2007. Monitoramento da Qualidade da Água de Poços no Calcário Jandaíra e Restrições na Agricultura Irrigada. Dissertação (Mestrado). Mossoró, Universidade Federal Rural do Semi-Árido.

Almeida, F. M., 2007. Estudo da Contaminação por Hidrocarbonetos em Postos de Serviços do Município de Abaetetuba - PA Utilizando Georadar. Dissertação (Mestrado). Belém, Universidade Federal do Pará.

Alvarenga, G., 2001. Nutrição: A importância dos nutrientes para uma vida saldável. Disponível: http://www.foreverliving.com.br/arqs/downloa ds/detalhe_1224594990_flp_cartilha_nutricao_ 22007121_web.pdf. Acesso: 18 dez. 2016.

ANA. Agência Nacional de Águas, 2010. Atlas Brasil. Abastecimento urbano de água: panorama nacional. Brasília.

ANA. Agência Nacional das Águas, 2011. Guia nacional de coleta e preservação de amostras: água, sedimento, comunidades aquáticas e efluentes líquidas. Brasília.

\begin{tabular}{|c|c|c|}
\hline$\sqrt{ } 21$ & TRALIAN & AND \\
\hline ZEALAN & ENVIRONI & \\
\hline
\end{tabular}

consumo. Assim, com relação à qualidade das amostras de água subterrânea pode-se aferir que as águas consumidas pelos moradores necessitam de um tratamento prévio, quanto aos padrões de potabilidade recomendados pelo Ministério da Saúde e pela Resolução 357/2005 do CONAMA.

Conclui-se que é de fundamental importância avaliar e realizar o monitoramento da qualidade das águas subterrâneas em nossa região. Tendo como finalidade proporcionar e fornecer aos moradores água com qualidade, assim como, informações a respeito da qualidade das águas que os mesmos utilizam para consumo.

CONSERVATION COUNCIL, 2000. Australian Water Quality Guidelines for Fresh and Marine Waters, National Water Quality Management Strategy. Canberra.

APHA. Standart Methods for the Examination of Water and Wastewater, 2005.APHA, AWWA, and WEF, $21^{\mathrm{a}}$. Edition.

Bastos, M. L., 2013. Caracterização da qualidade da água subterrânea: estudo de caso no município de cruz das almas - Bahia. Monografia (TCC). Bahia, Universidade Federal do Recôncavo da Bahia.

BRASIL, 2005. Resolução $n^{\circ}$ 357, de 17 de março de 2005. Brasília, DF.

BRASIL, 2006. Boas práticas no abastecimento de água: procedimentos para a minimização de riscos à saúde. Brasília: Ministério da Saúde, Secretaria de Vigilância em Saúde.

BRASIL, 2011. Portaria $\mathrm{n}^{\mathrm{o}} 2.914$, de 12 de dezembro de 2011. Brasília, DF.

BRASIL, 2014. Manual de controle da qualidade da água para técnicos que trabalham em ETAS. Brasília: Ministério da Saúde, Fundação Nacional de Saúde.

Carvalho, F. I. M., Lemos, V. P., Dantas filho, H. A., Dantas, K. G. F., 2015. Avaliação da qualidade das águas subterrâneas de Belém a partir de parâmetros físico-químicos e níveis de elementos traço usando análise multivariada. Revista Virtual de Química 7, 2221-2241. 
CDP. Companhia Docas do Pará, 2016. Diagnóstico ambiental do porto de vila do conde. Autoridade Portuária. Disponível: https://www.cdp.com.br/documents/10180/268 01/Diagn\%C3\%B3stico+ambiental_Porto+Org anizado+de+PVC.pdf/e2f88016-bdc5-4a389429-db142fd305c9. Acesso: 27 jan. 2017.

CETESB. Companhia Ambiental do Estado de São Paulo, 2009. Qualidade das águas interiores no estado de São Paulo: Significado ambiental e sanitário das variáveis de qualidade das águas e dos sedimentos e metodologias analíticas e de amostragem. São Paulo (Série Relatórios).

Condurú, M. T., 2012. Análise da qualidade da informação no setor de saneamento básico: em busca da inteligência estratégica. Tese (Doutorado). Belém, Universidade Federal do Pará.

CPRM. Serviço Geológico do Brasil. Geodiversidade do Estado do Pará, 2013. Disponível:

http://www.cprm.gov.br/publique/media/Geodi versidade_PA.pdf. Acesso: 04 dez. 2016.

Custódio, R., Llamas, M. R., 1983. Hidrologia Subterrânea, 28 ed. Ediciones Omega, Barcelona.

Dias, J.S., Neves, I., Silveira, V.H, 2012. Nutrientes: do que as plantas precisam?. Unifertil. Disponível: http://www.unifertil.com.br/admin/files/rc2012 1011151121.pdf. Acesso: 19 dez. 2016.

Feitosa, F.A.C., Filho, J. M., 2000. Hidrogeologia: Conceitos e Aplicações, 2 ed. LABHID - UFPE, Fortaleza.

Fernandes, A. M. F., 2011. Diagnóstico da qualidade da água subterrânea em propriedade rural no município de planalto, RS. Monografia (TCC). Ijuí, Universidade Regional do Noroeste do Estado do Rio Grande do Sul.

IBGE. Instituto Brasileiro de Geografia e Estatística, $2010 . \quad$ Disponível: http://www.ibge.gov.br/estadosat/perfil.php?si gla=pa. Acesso: 16 out. 2016.

Janzen, J. G., Schultz, H. E., Lamon, A. W., 2008. Medidas da concentração de oxigênio dissolvido na superfície da água. Revista Engenharia Sanitária e Ambiental [online] 3.
Disponível:

http://www.scielo.br/pdf/esa/v13n3/a06v13n3. pdf. Acesso: 02 dez. 2016.

Kemerich, P. D. C., 2008. Água Subterrânea e a Saúde da Comunidade em bairro de Santa Maria-RS. Dissertação (Mestrado). Santa Maria, Universidade Federal de Santa Maria.

\section{KPDES. KENTUCKY POLLUTANT} DISCHARGE ELIMINATION SYSTEM, 2010. Conductivity and Water Quality. Disponível:

http://kywater.org/ww/ramp/rmcond.htm.

Acesso: 08 dez. 2016.

Matta, M. A. S., Costa, F. R., Moraes, M. C. S., 2000. Águas superficiais e subterrâneas da região oeste da cidade de Belém/PA. Disponível:

https://aguassubterraneas.abas.org/asubterranea s/article/viewFile/23911/15975. Acesso: 05 dez. 2016.

Matta, M. A. S., Almeida, F. M., Dias, E. R. F., Bandeira, I. C. N., Figueiredo, A. B., 2004. Geometria dos sistemas aquíferos da bacia hidrográfica do Paracuri - Belém/PA, como base para uma proposta de abastecimento de água subterrânea. Disponível: https://aguassubterraneas.abas.org/asubterranea s/article/view/23486/15573. Acesso: 05 dez. 2016.

Menezes, J. P. C., 2012. Influência do uso e ocupação da terra na qualidade da água subterrânea e sua adequação para consumo humano e uso na agricultura. Dissertação (Mestrado). Alegre, Universidade Federal do Espirito Santo.

Reis, E., 1997. Estatística multivariada aplicada, 1 ed. Edições Sílabo, Lisboa.

Santos, A. A., 2008. Qualidade das Águas Superficiais e Subterrâneas na Área de Influência do Aterro Sanitário de Cuiabá - MT. Dissertação (Mestrado). Cuiabá, Universidade Federal de Mato Grosso.

Scuracchio, P. A., 2010. Qualidade da água utilizada para consumo em escolas no município de São Carlos - SP. Dissertação (Mestrado). Araraquara, Universidade Estadual Paulista. 
Revista Brasileira de Geografia Física v.11, n.03 (2018) 1026-1041.

Silva, R. C. A., Araújo, T. M., 2003. Qualidade da água do manancial subterrâneo em áreas urbanas de Feira de Santana (BA). Revista Ciência \& Saúde Coletiva [online] 8. Disponível: http://dx.doi.org/10.1590/S141381232003000400023. Acesso: 03 dez. 2016.
Zoby, J.L.G., Matos, B., 2002. Águas subterrâneas no Brasil e sua inserção na Política Nacional de Recursos Hídricos. Disponível: https://aguassubterraneas.abas.org/asubterranea s/article/viewFile/22634/14858. Acesso: 10 dez. 2016. 